11 Niklasson P, Lundbergh P, Strandell T. Prognostic factors in meningococcal disease. Scand $\mathcal{F}$ Infect Dis 1971;3:17-25.

2 Toews WH, Bass JW. Skin manifestations of meningococcal infection. An immediate indicator of prognosis. Am F Dis Child 1974;127:173-6.

13 Tonjum T, Nilsson F, Bruun JN, Haneberg B. The early phase of meningococcal disease. NIPH Ann 1983;6:175-81.

4 Banks HS. Meningococcosis. A protean disease. Lancet 1948;ii:635-40, $677-81$

15 Slack J. Deaths from meningococcal infection in England and Wales in 1978. I R Coll Physicians Lond 1982;16:40-4.

16 Talan DA, Hoffman JR, Yoshikawa TT, Overturf GD. Role of empiric antibiotics prior to lumbar puncture in suspected bacterial meningitis: state

17 Oakley JR, Stanton AN. Meningococcal infections during infancy: confidential enquiries into 10 deaths. BMF 1979;ii:468-9.

18 Department of Health and Social Security. Meningococcal infection: meningitis and septicaemia. London: DHSS, 1988. (PL/CMO(88)2.)

19 Drugs for the doctor's bag 1989. Drug Ther Bull 1989:27:17-9.

20 Abramson JS, Spika JS. Persistence of Neisseria meningitidis in the upper respiratory tract after intravenous antibiotic therapy for systemic meningococcal disease. F Infect Dis 1985;151:370-1.

21 Jones DM, Kaczmarski EB. Meningococcal infections in England and Wales: report of the Meningococcal Reference Laboratory for 1991. Communicable Disease Report 1992;2:R61-3.

22 Dean AG, Dean JA, Burton JH, Dicker RC. Epi Info, Version 5: a wordprocessing, database, and statistics program for epidemiology on microcomputers. Atlanta: Centers for Disease Control, 1990.

23 Strang JR, Pugh EJ. Meningococcal infections: reducing the case fatality rate by giving penicillin before admission to hospital. $B M \mathcal{J}$ 1992;305:141-3.

24 Talan DA, Guterman JJ, Overturf GD, Singer C, Hoffman JR, Lambert B. Analysis of emergency department management of suspected bacterial Analysis of emergency department managen

25 Gedde-Dahl TW, Hoiby EA, Brandtzaeg P, Eskerud JR, Bovre K. Some arguments on early hospital admission and treatment of suspected meningococcal disease cases. NIPH Ann 1990;13:45-60.

26 Brandtzaeg P, Kierulf P, Gaustad P, Skulberg A, Bruun JN, Halvorsen S, et al. Plasma endotoxin as a predictor of multiple organ failure and death in systemic meningococcal disease. F Infect Dis 1989;159:195-204.

27 Waage A, Halstensen A, Espevik T. Association between tumour necrosi factor in serum and fatal outcome in patients with meningococcal disease. Lancet 1987;i:355-7.

28 Waage A, Brandtzaeg P, Halstensen A, Kierulf P, Espevik T. The complex pattern of cytokines in serum from patients with meningococcal septic shock. Association between interleukin 1 , interleukin 6, and fatal outcome. f Exp Med 1989;169:333-8.

29 Andersen BM, Solberg $\mathrm{O}$. The endotoxin-liberating effects of antibiotics on meningococci in vitro. Acta Pathologica et Microbiologica Scandinavica $(B)$ 1980;88:231-6

30 Mellado MC, Rodriguez-Contreras R, Mariscal A, Luna JD, Delgado Rodriguez M, Galvez-Vargas R. Effect of penicillin and chloramphenicol on the growth and endotoxin release by $\mathrm{N}$ meningitidis. Epidemiol Infect the growth and $1991 ; 106: 283-8$.

31 Goldacre MJ. Acute bacterial meningitis in childhood: aspects of prehospita care in 687 cases. Arch Dis Child 1977;52:501-3.

32 Edwards EA, Devine LF, Sengbusch $\mathrm{CH}$, Ward HW. Immunologica investigations of meningococcal disease. III. Brevity of group $\mathrm{C}$ acquisition prior to disease occurrence. Scand f Infect Dis 1977;9:105-10.

33 Stephens DS, Farley MM. Pathogenic events during infection of the huma nasopharynx with Neisseria meningitidis and Haemophilus influenzac. Rev Infect Dis 1991;13:22-33.

34 Cartwright KAV, Jones DM. Value of throat swabs from index cases of meningococcal meningitis. $\mathcal{F}$ Clin Pathol 1990;43:438.

35 Sippel JE, Girgis NI. Throat culture from patients with meningococcal meningitis. F Clin Pathol 1990;43:610-1.

36 Ong ELC, Dunbar EM. Antibiotics carried in general practitioners' emergency bags. $B M 7$ 1988;297:901

37 Converse GM, Gwaltney JM, Strassburg DA, Hendley JO. Alteration of cerebrospinal fluid findings by partial treatment of bacterial meningitis. I Pediatr 1973;83:220-5

38 Jarvis $\mathrm{CW}$, Saxena KM. Does prior antibiotic treatment hamper the diagnosis of acute bacterial meningitis? Clin Pediatr 1972;11:201-4.

39 Partially treated meningitis. Lancet 1974; i:55-6.

40 Baxter P, Priestley B. Meningococcal rash. Lancet 1988;i:1166-7.

41 Surtees SJ, Stockton MG, Gietzen TW. Allergy to penicillin: fable or fact? BMF 1991;302:1051-2.

Accepted 15 May 1992)

\title{
Follow up of patients presenting with fatigue to an infectious diseases clinic
}

\author{
Michael Sharpe, Keith Hawton, Valerie Seagroatt, Geoffrey Pasvol
}

University of Oxford, Oxford

Michael Sharpe, clinical tutor, department of psychiatry Keith Hawton, clinical lecturer, department of psychiatry

Valerie Seagroatt, statistician, unit of health care epidemiology, department of public health and primary care

\section{Nuffield Department of} Medicine, John Radcliffe Hospital, Oxford Geoffrey Pasvol, consultant physician

Correspondence to: Dr M Sharpe, University Department of Psychiatry, Warneford Hospital, Oxford OX3 7JX.

BMF 1992;305:147-52
Abstract

Objectives-To determine the symptomatic and functional status during follow up of patients referred to hospital with unexplained fatigue and to identify patient variables associated with persistent functional impairment.

Design-Follow up by postal questionnaire six weeks to four years (median 1 year) after initial clinical assessment of patients referred to hospital during 1984-8.

Setting-Infectious diseases outpatient clinic in a teaching hospital.

Patients -200 consecutive patients with fatigue of uncertain cause for at least six weeks; 177 fulfilled the inclusion criteria.

Main outcome measures-Findings at initial assessment; current symptoms, beliefs about the cause of illness, coping behaviours emotional disorder, social variables including membership of self help organisations, and degrees of recovery and functional impairment from questionnaire responses.

Results-144 (81\%) patients returned completed questionnaires. Initial assessment did not indicate the cause of fatigue, other than preceding infection. The proportion of patients with functional impairment was significantly smaller with longer follow up $(33 \%(11 / 33)$ at two to four years, $73 \%(29 / 40)$ at six weeks to six months; $\chi^{2}$ for trend $=12 \cdot 5, \mathrm{df}=1$; $\mathbf{p}<\mathbf{0 . 0 5}$ ). Functional impairment was significantly associated with belief in a viral cause of the illness (odds ratio $=3.9 ; 95 \%$ confidence interval 1.5 to 9.9 ), limiting exercise $(3.2 ; 1.5$ to 6.6$)$, avoiding alcoho $(4.5 ; 1.8$ to 11.3$)$, changing or leaving employment $(3.1 ; 1.4$ to 6.9$)$, belonging to a self help organisation $(7.8 ; 2.5$ to 23.9$)$, and current emotional disorder $(4 \cdot 4 ; 2 \cdot 0$ to $9 \cdot 3)$.
Conclusions-Short term prognosis for recovery of function was poor but improved with time. Most patients had made a functional recovery by two years after initial clinic attendance. Impaired functioning was more likely with certain patient characteristics. Prospective studies are required to clarify whether these associations are the consequences of a more disabling illness or indicate factors contributing to impaired function.

\section{Introduction}

In recent years there has been renewed interest in the causes and management of the symptom of fatigue. Although fatigue is a symptom of many medical conditions, identifiable organic disease is rarely found in patients referred to hospital with fatigue as a major complaint. ${ }^{12}$ The fatigue is then considered to be "idiopathic." Clinical concern has focused on patients whose fatigue is idiopathic, persistent, and associated with impaired physical and mental functioning, who have been referred to as having a "chronic fatigue syndrome" if the fatigue has been present for at least six months. ${ }^{3}$ The patient group thus defined is almost certainly aetiologically and prognostically heterogeneous. Several more specific syndromes have been proposed, including more restrictively defined chronic fatigue syndromes, ${ }^{45}$ postviral fatigue syndrome,${ }^{6}$ and myalgic encephalomyelitis. ${ }^{7}$ Although each has its advocates, none of these specific syndromes has yet been shown to have clinical utility.

The literature includes several studies of patients with idiopathic fatigue, most of which have selected patients according to one of the above criteria. However, there is still a paucity of information concerning unselected patients referred to non-specialist units. The patient samples of previous studies have been 
obtained from self referrals, ${ }^{5 *}$ primary care, ${ }^{911}$ or tertiary referral centres. ${ }^{561213}$ The generalisability of the findings to a general hospital outpatient clinic is therefore in doubt.

The prognosis for such patients is also uncertain. Conflicting findings have been reported for patients with idiopathic fatigue in primary care, ${ }^{9-11}$ whereas the prognosis for patients referred to hospital with "postviral syndrome" has been reported as poor. ${ }^{6}$ There are no long term follow up studies of large series of patients with idiopathic fatigue, and the factors associated with persistent illness are unclear. It has been suggested that patients may fail to recover from acute fatigue if they become trapped in a vicious circle of avoidance of activity, belief in an infective cause outside their control, and emotional disorder. ${ }^{1+}$ Though patients who regard their illness as physical rather than psychological in origin respond less well to psychological treatment, ${ }^{15}$ the significance of such beliefs and consequent behaviours in an untreated population is unknown.

In this report we present findings from a large consecutive series of patients who presented with a major complaint of fatigue to a single physician working in an infectious diseases clinic. Patients were subsequently followed up by postal questionnaire. The study attempted to answer two questions: ( $a$ ) What is the outcome for patients with fatigue in terms of symptoms and limitations on their functioning? and (b) What patient factors are associated with persistent functional impairment?

\section{Patients and methods}

\section{CLINIC REFERRALS}

Two hundred consecutive patients with a major complaint of fatigue of at least six weeks' duration were assessed in an infectious diseases clinic between November 1984 and December 1988 by one consultant physician (GP) as part of his routine clinical practice. The referrals were unsolicited from general practitioners. All patients had a major complaint of fatigue and had impaired physical and mental function because of this. A minimum of six weeks' fatigue was required for their inclusion in the study.

\section{INITIAL ASSESSMENT}

In all cases age, sex, marital status, and the date of onset of the illness reported by the patient were recorded, a detailed history was taken, and a full physical examination was performed. In almost all patients a full blood count and biochemical testing were carried out. (Specific tests including antibodies to acetylcholine receptor, ${ }^{16}$ large undifferentiated cell counts which might suggest recent viral infection, ${ }^{17}$ and detection of VP1 antigen ${ }^{18}$ were performed only in selected patients.)

\section{MANAGEMENT}

Most patients were seen only once after the initial assessment, to give them the results of investigations. Treatment consisted principally of establishing the absence of treatable disease; acknowledging the reality of the patient's illness; diagnosing "post infectious" or "idiopathic" fatigue; and optimistic reassurance about prognosis. Twenty $(10 \%)$ patients were admitted to the infectious disease ward for further investigation.

\section{FOLLOW UP QUESTIONNAIRE}

After 12 patients who were aged under 16 years, 10 patients for whom the reported onset of illness was less than three months before follow up, and one patient who was blind were excluded, 177 patients remained.
These patients were all sent a previously piloted questionnaire in February 1989. The study was approved by the local ethics committee.

The questionnaire (available from the authors) asked patients about their health over the previous month on four point scales. The questions were based on clinical experience intended to determine the patients' current state and experience of treatment and also to inquire about factors perpetuating illness, as suggested by a cognitive behavioural model of the chronic fatigue syndrome. ${ }^{14}$ It included the following items: symptoms such as fatigue and muscle pain (rated as "absent" to "present most of the time"); functional impairment in terms of patients' premorbid performance in walking, social life, hobbies, and occupation (rated as "not impaired" to "impaired a great deal"); social factors such as changes in employment or studies and membership of a patient organisation; the patients' beliefs about the cause of their illness (three point scales from "not a cause" to "definitely a cause"); the methods of coping with symptoms they had found helpful when ill, including limiting exercise and avoiding alcohol (four point scale from "no help" to "very helpful"); and finally, patients' evaluation of any treatment received (four point scale from "no help" to "very helpful"). Patients were also asked to rate their degree of recovery (three point scale from "none" to "fully recovered").

Included in the questionnaire was the hospital anxiety and depression scale. ${ }^{17}$ This scale was designed to assess emotional disorder in physically ill subjects and is relatively free from somatic items. The total score was used with a threshold of $11 / 12^{20}$ (calculated both including and excluding the fatigue related symptom of "I feel as if I am slowed down").

\section{ANALYSIS}

The questionnaire responses were collapsed into dichotomous categories: symptoms were rated as present if reported as occurring "frequently" or "most of the time" over the past month; each belief was scored as present if it was rated as a "possible" or "definite" cause of illness; specific areas of activity were rated as impaired if affected at least "moderately"; and each coping behaviour was rated as present if it was reported "moderately helpful" or "very helpful."

Functional impairment was used as the principal measure of outcome. Patients were considered to have impaired functioning if one or more of the activities assessed (housework, sport, walking, social, hobbies, occupation, or studies) had been impaired by the illness during the preceding month. The associations between impaired overall functioning, duration of $\tilde{N}$ follow up, demographic variables, beliefs, emotional disorder, coping behaviours, and social variables were examined by logistic regression fitted using generalised linear interactive modelling. ${ }^{21}$ Each of these possible explanatory variables was fitted both unadjusted and after adjustment for other variables. For confounding associations the significance of the association was assessed by the increase in deviance found when that variable was excluded from the regression (the change in deviance was approximated to a $\chi^{2}$ statistic). Odds ratios for functional impairment at follow up are reported relative to a reference value of each variable and were calculated as the exponential of the parameter of the fitted model.

\section{Results}

INITIAL ASSESSMENT

All 200 patients were judged on clinical assessment to have fatigue with impaired functioning as their major complaint. Of these, $131(66 \%)$ had reported disabling fatigue for six months or more at presentation 옹 
and so would have met the accepted time criteria for the chronic fatigue syndrome. ${ }^{3}$

Of the whole sample, $166(83 \%)$ patients related the onset of symptoms to an acute illness. The most common initial symptoms, reported by $93(47 \%)$ patients, were those of an upper respiratory tract infection (that is, sore throat, fever, and swollen glands). Other retrospectively reported symptoms suggesting an initial infection were diarrhoea in 17 patients (acquired while abroad in 13) and chest pain in four. An initiating disease (or treatment) had been recorded in a small number of patients: pneumonia, viral meningitis, epididymitis, immunisation against tetanus, and a fracture (one patient each); 35 (18\%) patients reported no initiating illness.

Physical examination disclosed no major abnormalities. Minor abnormalities were found in $18(9 \%)$ patients (soft systolic murmurs in nine, blood pressure $>140 / 90 \mathrm{~mm} \mathrm{Hg}$ in three, and minor cervical lymphadenopathy in six), none of which enabled a firm physical diagnosis to be made. Psychiatric assessments were not performed at presentation.

Laboratory investigations added little to the clinical assessment. A full blood count was obtained in 184 (92\%) patients; three patients had white counts $>10 \times 10^{9} / 1$; five had eosinophil counts $>0.5 \times 10^{9} / 1$; five had an erythrocyte sedimentation rate $>30 \mathrm{~mm}$ in the first hour; and five had platelet counts $>3.5 \times 10^{12} / 1$. Biochemical variables were studied in $192(96 \%)$ patients and disclosed minor abnormalities in bilirubin (three patients), aspartate transaminase (six) and alkaline phosphatase (five). The large undifferentiated cell counts were normal $(0.2 \%$ to $1.1 \%)$ in 16 patients tested. Nine of $20(45 \%)$ patients with the chronic fatigue syndrome were positive for VPl antigen. ${ }^{18}$ Only two patients had slightly raised creatinine kinase concentration (264 and 274 IU/1 respectively; reference value $<200 \mathrm{IU} / \mathrm{l}$ ). None of 24 patients complaining of severe muscle weakness had acetylcholine receptor antibodies. ${ }^{16}$ None of these findings led to specific treatment.

\section{QUESTIONNAIRE FOLLOW UP SAMPLE}

Of the 177 questionnaires sent out, 144 responses were available for analysis (response rate $81 \%$ ). Five patients could not be traced (questionnaire returned) and 28 questionnaires were either not returned or were inadequately completed. The patients in the final sample had a median age of 34 years (range 16 to 79 years); $94(65 \%)$ were female. The median duration of fatigue at presentation to the clinic was 25 months (range 6 weeks to 25 years), and the time that elapsed between presentation and questionnaire follow up ranged from six weeks to four years (median one year). The characteristics of the follow up sample were as follows.

Functional impairment and employment/studies-In all, $130(90 \%)$ patients reported having reduced their normal activities by at least half for a month or more at some time during their illness. Fifty five (38\%) had left or changed their job (or studies) because of their illness and $93(65 \%)$ were functionally impaired at follow up.

Beliefs about the cause of the illness-Many patients attributed their illness to more than one cause. One hundred and thirty five (94\%) believed that infection had been a factor, $120(83 \%)$ suggesting a virus as the infective agent. However, $97(67 \%)$ considered "stress" to have played a part in causing their illness.

Symptoms-The only symptoms reported as frequently present over the previous month by at least half the sample were fatigue $(115,80 \%)$ patients and muscle pain $(61,42 \%)$.

Ways of coping with symptoms-Seventy one (49\%) patients had found limiting exercise helpful when they were ill, and $46(32 \%)$ had found it helpful to avoid alcohol. Many respondents commented that they tried to avoid "all kinds of stress" as failure to do so tended to cause a "relapse" of symptoms. A minority of patients $(41,28 \%)$ had joined a patients' organisation (ME Association or ME Action Campaign).

Emotional disorder (anxiety and depression) as defined by a total score of greater than 11 on the hospital anxiety and depression scale was present in $95(66 \%)$ patients, and in $81(56 \%)$ if the scale item "slowed down" was excluded.

Treatment-In addition to the attendance at the infectious diseases outpatient clinic many patients had sought further treatment for their fatigue. Twenty three $(16 \%)$ had attended a psychiatric outpatient clinic but only five patients found it more than "slightly helpful." Fifty five of the sample (38\%) had taken an antidepressant drug, of whom only four reported that they had been "greatly improved" whereas 13 patients felt they had been "made worse" by the drug. Other forms of therapy included dietary advice, principally concerning diets to control candida infection (39, $27 \%)$, homeopathy $(29,20 \%)$, physiotherapy (18, $13 \%)$ and hypnosis $(7,5 \%)$. None of the above treatments were reported to have been "very helpful" by more than $30 \%$ of the patients who had received it. However, $71(49 \%)$ patients reported finding the initial outpatient medical assessment "very helpful."

\section{FUNCTIONAL IMPAIRMENT AT FOLLOW UP}

At the time of follow up only $19(13 \%)$ patients regarded themselves as "fully recovered." The remainder reported excessive fatigue and varying degrees of functional impairment. Ninety three $(65 \%)$ were functionally impaired according to our definition, most reporting impairment in several different activities (walking $90 \mathrm{~m}$ (100 yards) (72), social activities (44), hobbies (53), and occupation (44)). Most patients $(68,73 \%)$ had experienced days during the past month when they had been entirely unable to work or study because of fatigue.

All the functionally impaired patients complained of “excessive fatigue;" $54(58 \%)$ reported frequent muscle pain, $53(57 \%)$ frequent headache, and $42(53 \%)$ poor concentration. Most $(64,69 \%)$ complained of problems with sleep, $50(53 \%)$ of disturbed sleep, and $39 \%$ (36/93) of an increased need for sleep. Emotional disorder was present in $69(73 \%)$ and in $64(69 \%)$ if the item "slowed down" was excluded.

Dividing the patient sample into subgroups according to duration of follow up (table I) disclosed that the percentage of patients functionally impaired by the illness was smaller in patients with longer periods of follow $\operatorname{up}\left(\chi^{2}\right.$ for trend $\left.=12.5, \mathrm{df}=1 ; \mathrm{p}<0.05\right)$. Though functional impairment was present in $73 \%$ (29/40) of patients who completed their follow up questionnaire within six months of the initial clinic assessment, only $33 \%$ (11/33) of patients followed up at two to four years were so affected. Despite this indication of improvement in functioning with time, most of these longer term follow up patients $(23,70 \%)$ continued to consider themselves unwell and to complain of fatigue (see table I).

TABLE I-Persistence of fatigue and functional impairment by duration of follow up

\begin{tabular}{lccc}
\hline Duration of follow up & No of patients & $\begin{array}{c}\text { No (\%) with } \\
\text { symptoms }\end{array}$ & $\begin{array}{c}\text { No (\%) } \\
\text { functionally } \\
\text { impaired }\end{array}$ \\
\hline <6 Months & 40 & $36(90)$ & $29(73)$ \\
6 months-1 year & 42 & $39(93)$ & $33(79)$ \\
1-2 years & 29 & $27(93)$ & $20(69)$ \\
2-4 years & 33 & $23(70)$ & $11(33)$ \\
\hline Whole sample & 144 & $125(87)$ & $93(65)$ \\
\hline
\end{tabular}




\begin{tabular}{|c|c|c|c|c|c|c|c|}
\hline Variable & No of patients & $\begin{array}{l}\text { No }(\%) \text { of patients with } \\
\text { functional impairment }\end{array}$ & Odds ratio & $\begin{array}{l}95 \% \text { Confidence } \\
\text { interval }\end{array}$ & $\begin{array}{l}\text { Degrees of } \\
\text { freedom }\end{array}$ & $\chi^{2}$ & $\begin{array}{l}\text { Adjusted odds } \\
\text { ratiof }\end{array}$ \\
\hline \multicolumn{8}{|c|}{ Duration of follow up: } \\
\hline$<6$ months $\ddagger$ & 40 & $29(73)$ & 1 & & 3 & $18 \cdot 6^{\star}$ & \\
\hline $6-12$ months & 42 & $33(79)$ & $1 \cdot 4$ & 0.5 to 3.9 & & & \\
\hline $1-2$ years & 29 & $20(69)$ & $0 \cdot 8$ & 0.3 to 2.5 & & & \\
\hline $2-4$ years & 33 & $11(33)$ & $0 \cdot 2$ & 0.1 to 0.5 & & & \\
\hline \multicolumn{8}{|c|}{ Onset of symptoms to initial assessment: } \\
\hline$<6$ months $\ddagger$ & 32 & $19(60)$ & 1 & & 3 & $4 \cdot 1$ & \\
\hline 6-12 months & 32 & $21(66)$ & $1 \cdot 3$ & 0.5 to 3.3 & & & 1.0 \\
\hline $1-2$ years & 31 & $18(58)$ & $0 \cdot 9$ & 0.4 to $2 \cdot 4$ & & & $0 \cdot 6$ \\
\hline $2-4$ years & 29 & $23(79)$ & $2 \cdot 6$ & 0.9 to 7.6 & & & 0.9 \\
\hline \multicolumn{8}{|l|}{ Sex: } \\
\hline Maleł & 51 & $32(63)$ & $0 \cdot 1$ & 1 & 1 & $0 \cdot 1$ & \\
\hline Female & 93 & $61(66)$ & $1 \cdot 1$ & 0.5 to $2 \cdot 3$ & & & $1 \cdot 3$ \\
\hline \multicolumn{8}{|l|}{ Age (years): } \\
\hline $16-25 \ddagger$ & 36 & $24(67)$ & 1.9 & 1 & 2 & 1.9 & \\
\hline $26-40$ & 60 & $35(58)$ & $0: 7$ & 0.3 to 1.7 & & & 0.9 \\
\hline $41-79$ & 48 & $34(71)$ & $1 \cdot 2$ & 0.5 to 3.1 & & & 1.9 \\
\hline \multicolumn{8}{|l|}{ Marital status: } \\
\hline Single & 58 & $39(67)$ & 1 & & 2 & $1 \cdot 3$ & \\
\hline Married & 77 & $61(47)$ & $0 \cdot 8$ & 0.4 to 1.6 & & & $0 \cdot 9$ \\
\hline Divorced or & & & & & & & \\
\hline \multirow{2}{*}{\multicolumn{8}{|c|}{ Belief in virus infection: }} \\
\hline & & & & & & & \\
\hline Noł & 24 & $9(37)$ & 1 & & 1 & $8 \cdot 8^{\star}$ & \\
\hline Yes & 120 & $84(70)$ & $3 \cdot 9$ & 1.5 to $9 \cdot 9$ & & & $3 \cdot 3$ \\
\hline \multicolumn{8}{|c|}{ Limitation of exercise: } \\
\hline Noł & 73 & $38(52)$ & 1 & & 1 & $7 \cdot 6^{\star}$ & \\
\hline Yes & 71 & $55(77)$ & $3 \cdot 2$ & 1.5 to 6.6 & & & $2 \cdot 9$ \\
\hline \multicolumn{8}{|c|}{ Avoidance of alcohol: } \\
\hline Noł & 98 & $54(55)$ & 1 & & 1 & $13 \cdot 1^{\star}$ & \\
\hline \multirow{2}{*}{\multicolumn{8}{|c|}{ Changed job or stopped work: }} \\
\hline & & & & & & & \\
\hline No $\ddagger$ & 90 & $50(56)$ & 1 & & 1 & $9 \cdot 0^{\star}$ & \\
\hline Yes & 54 & $43(80)$ & $3 \cdot 1$ & 1.4 to 6.9 & & & $2 \cdot 9$ \\
\hline \multicolumn{8}{|c|}{ Member of patient organisation: } \\
\hline Noł & 103 & $56(54)$ & 1 & & 1 & $19 \cdot 0^{\star}$ & \\
\hline \multirow{2}{*}{\multicolumn{8}{|c|}{ Emotional disorder (total hospital anxiety and depression score): }} \\
\hline & & & & & & & \\
\hline$<12 \ddagger$ & 49 & $24(49)$ & 1 & & 1 & $7 \cdot 8^{\star}$ & \\
\hline$\geqslant 12$ & 95 & $69(73)$ & $2 \cdot 8$ & 1.3 to 5.8 & & & $2 \cdot 5$ \\
\hline \multicolumn{8}{|c|}{ Emotional disorder (hospital anxiety and depression score, excluding item "slowed down"): } \\
\hline$<12 \ddagger$ & 63 & $29(46)$ & 1 & & 1 & $4 \cdot 2^{\star}$ & \\
\hline$\geqslant 12$ & 81 & $64(79)$ & $4 \cdot 4$ & $2 \cdot 0$ to $9 \cdot 3$ & & & $4 \cdot 2$ \\
\hline
\end{tabular}

TABLE III - Factors independently associated with functional impairment at follow up according to logistic models

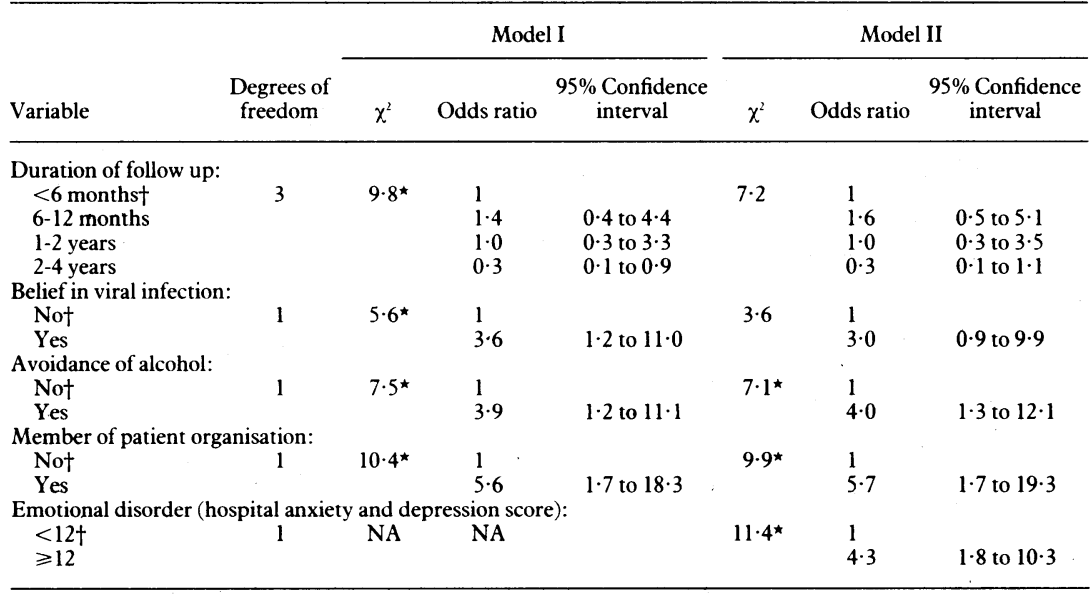

${ }^{\star} \chi^{2}$ statistic (for reduction in deviance) significant at $5 \%$ level.

†Reference category.

The number of referrals to the clinic increased over the four years (table I), raising the possibility that there were initial differences between follow up groups. This is unlikely, however, as there were no significant differences on any of the independent variables between those patients seen more than two years before follow up and those seen more recently.

Interestingly, there seemed to be little difference in functional impairment at follow up between patients who had been ill for more than six months at initial assessment and hence met the criteria for the chronic fatigue syndrome $\mathrm{e}^{3}$ at this time and those with shorter histories (see table II)

ASSOCIATIONS WITH FUNCTIONAL IMPAIRMENT AT FOLLOW UP

Age, sex, and marital status were not significantly related to functional impairment. Significant associations were found with patients' beliefs, coping behaviours, and social factors. The specific factors were the belief that fatigue was a consequence of an initial viral infection; coping with illness by limiting exercise and by avoiding alcohol; changing or leaving a job or studies, and joining a patient organisation (see table II). Emotional disorder at the time of follow up was also associated with functional impairment.

Two further analyses were undertaken to examine these associations. Firstly, as time since initial clinic attendance may have been a confounding factor the analysis was repeated after adjusting for this variable. The adjustment had little effect on the odds ratios for the associations reported above (table II). Secondly, 오 because the explanatory belief, behaviour, and social $N$ variables were correlated, the associations of each with functional impairment was re-examined after adjustment for all the others. When this was done the following associations remained: duration of follow up $\mathrm{N}$ $\left(\chi^{2}\right.$ for trend $\left.=6 \cdot 1, \mathrm{df}=1 ; \mathrm{p}<0.05\right)$ and a belief in an initial virus infection, avoidance of alcohol, and membership of a patient organisation. Table III (model I) shows the odds ratios and $\chi^{2}$ values for $\mathbb{E}$ exclusion of each term obtained from the logistic model containing these variables as main effects.

The association of emotional disorder with functional impairment remained significant after adjustment for all other measured variables. Including emotional disorder in the logistic model resulted in minor changes to the estimated odds ratios as shown in table III 8 (model II). The association for duration of follow up? was no longer significant for the specific follow up categories, although $\chi^{2}$ for trend remained so $\left(\chi^{2}=4 \cdot 1\right.$, $\mathrm{df}=1 ; \mathrm{p}=0.05)$. The value of $\chi^{2}$ for the association of belief in viral infection $(p=0.07)$ was reduced to below that for significance. However, the association of avoidance of alcohol and membership of a patient 
organisation remained significant after adjustment, suggesting that their association with functional impairment is independent of emotional disorder.

\section{Discussion}

This study is the first systematic follow up of a large number of consecutive patients with fatigue referred by general practitioners to an infectious diseases clinic in the United Kingdom. Its principal weaknesses are the reliance on questionnaire responses and the fact that many patient variables were assessed only at follow up. These findings therefore require confirmation in a prospective study. Furthermore, though our sample may be typical of patients referred to infectious diseases clinics, it may not be representative of patients referred to other specialist clinics or those with fatigue who are not referred to hospital.

The results of the initial clinical assessment confirm that physical examination and routine laboratory investigations rarely yield evidence of treatable disease other than "post infectious fatigue syndrome." 2 Our findings also illustrate that despite this absence of abnormalities on routine laboratory investigation the functional and occupational morbidity in these patients is considerable. Most patients had been unable to work for prolonged periods and a significant proportion (38\%) had abandoned employment or studies altogether.

Perhaps not surprisingly for patients attending an infectious diseases clinic, most believed that their illness had been caused by infection, most commonly a virus. It was, however, impossible to determine the veracity of this belief in more than a few patients. Attributions for the cause of the illness were frequently complex, and many patients also referred to the role of "stress." Most patients had found limiting exercise helpful as a method of coping with their symptoms. Other behaviours commonly avoided included eating certain foods, drinking alcohol, and doing anything that might lead to "stress." In addition most patients had emotional disorder as defined by their total score on the hospital anxiety and depression scale.

\section{FUNCTIONAL IMPAIRMENT AT FOLLOW UP}

Our findings confirm a previous report from primary care suggesting a poor prognosis for the first year after clinic attendance. ${ }^{9}$ However, the longer term follow up suggests that the proportion of patients remaining functionally impaired falls as time passes, with most patients no longer having impairment after two years. On the other hand, it is noteworthy that most patients remain symptomatic, and one third remain functionally impaired for as long as two to four years after their initial clinic attendance.

We have no reason to suppose that patients who were referred to the clinic more recently had a different degree of disability from those referred earlier. Indeed, there was no substantial difference in length of history, age, or sex distribution over the period studied. However, because disability was not formally measured at the initial clinic assessment, initial differences between the follow up groups cannot be entirely excluded.

\section{ASSOCIATIONS WITH FUNCTIONAL IMPAIRMENT AT} OUTCOME

Length of history at presentation did not predict functional impairment at follow up. We did not find any difference in prognosis between patients who met the time criteria for the chronic fatigue syndrome by having been ill for more than six months at presentation and those with shorter histories. This result casts doubt on the utility of the existing time criteria for the syndrome. ${ }^{3-5}$

Functional impairment was associated with several patient factors, including belief in a viral cause, leaving or changing employment, coping with illness by avoidance of exercise and alcohol, membership of a patient organisation, and emotional disorder. These factors are themselves associated but the last three remain independently associated with impairment after all the others have been controlled for. Though these results are of interest and relevant to a cognitive behavioural explanation of the perpetuation of the chronic fatigue syndrome, they should be interpreted with caution for the following reasons. Firstly, the confidence intervals around the odds ratios are wide, and hence there is considerable uncertainty about the strength of the associations. Secondly, the independen variables were assessed at the questionnaire follow up not at the initial clinic assessment, and cannot therefore be regarded as predictors of poorer outcome. Thirdly other patient variables which were not measured, such as dysfunction of the immune system,,$^{22}$ may be important. Finally, the findings do not indicate the direction of cause underlying the associations.

With these caveats in mind we will briefly conside the clinical significance of the findings. Although the analysis suggests that the findings are unlikely to be simple reflections of chronicity, the associated factors may be consequences of a more severe form of illness. Alternatively, they may indicate factors that tend to maintain functional impairment. Thus membership of a patient organisation may be an understandable consequence of a more disabling illness or, alter natively, could be a marker of beliefs in physical causation and the need to limit activity which may perpetuate illness. Emotional disorder, which has a prevalence in the functionally impaired patients in this sample similar to that found in previous studies, ${ }^{81213}$ may be a consequence of the distress resulting from severe disability or may be a factor contributing to the functional impairment. ${ }^{23}$ It is of course possible that the cause underlying the above associations could act in both directions; thus emotional distress may be both a cause and consequence of functional impairment. ${ }^{14}$

The strong association between avoidance of alcohol and functional impairment is intriguing. It may be a marker of physiological abnormality or of avoidance of an activity that exacerbates the feeling of fatigue. It merits further investigation.

\section{MANAGEMENT}

This study is not able to evaluate specifically the effect of the physician's explanation and reassurance. However, though most patients reported finding it helpful, the poor short term prognosis indicates its ineffectiveness. Many patients had taken "alternative" remedies but with little benefit. Notably, despite the high prevalence of emotional disorder few patients had attended a psychiatric outpatient clinic and even fewer found their contact with psychiatric services beneficial. Although commonly recommended as a treatment for chronic fatigue, ${ }^{24}$ antidepressant drugs were found by few patients to be beneficial. Hence it seems that currently available forms of treatment, including psychiatric outpatient care, are not meeting the needs of this patient group. More effective treatments are therefore required.

In conclusion, routine laboratory assessment is unlikely to yield evidence of treatable disease in patients referred to hospital with unexplained fatigue. The functional impairment of patients with the chronic fatigue syndrome is severe, but our results suggest that the prognosis for functional recovery by two to four years after clinic assessment is good. Many patients remain symptomatic, however, and a significant minority remain chronically disabled. Functional impairment at follow up is not predicted by demographic variables or by length of history at presentation. 
Patients who are functionally impaired are more likely to have emotional disorder, to believe in an infectious cause for their illness, to avoid alcohol, and to be members of a patient self help organisation. Prospective studies are required to determine the aetiological importance of these associations.

We thank Penny Hagar and Susan Simkin for handling and scoring the questionnaires, and Oxfordshire Health Authority for financial support.

1 Valdini A, Steinhardt S, Feldman E. Usefulness of a standard battery of laboratory tests in investigating chronic fatigue in adults. Fam Pract 1989;6:286-91.

2 Lane TJ, Matthews DA, Manu P. The low yield of physical examinations and laboratory investigations of patients with chronic fatigue. $\mathrm{Am} \mathcal{J ~ M e d ~} \mathrm{Sci}$ 1990;299:313-8.

3 Sharpe M, Archard LC, Banatvala JE, Borysiewicz LK, Clare AW, David A, et al. A report-chronic fatigue syndrome: guidelines for research. $\mathcal{I} R$ Soc Med 1991;84:118-21.

4 Holmes GP, Kaplan JE, Gantz NM, Komaroff AL, Schonberger LB, Straus SE, et al. Chronic fatigue syndrome: a working case definition. Ann Intern

5 Hickie I, Lloyd A, Wakefield D, Parker G. The psychiatric status of patients with chronic fatigue syndrome. Br f Psychiatry 1990;156:534-40.

6 Behan PO, Behan MH. Postviral fatigue syndrome. Crit Rev Neurobiol 1988:4:157-79.

Dowsett EG, Ramsay AM, McCartney RA, Bell EJ. Myalgic encephalomyelitis: a persistent enteroviral infection? Postgrad Med f 1991;66:526-30. Manu P, Matthews DA, Lane TJ, Tennen H, Hesselbrock V, Mendola R, et al. Depression among patients with a chief complaint of chronic fatigue. 7 Affective Disord 1991;17:165-72.

9 Kroenke K, Wood DR, Mangelsdorff D, Meier NJ, Powell JB. Chronic fatigue in primary care; prevalence, patient characteristics, and outcome. JAMA 1988;260:929-34

10 Valdini AF, Steinhardt S, Valicenti J, Jaffe A. A one year follow up of fatigued patients. F Fam Pract 1988;26:33-8.

11 Nelson E, Kirk J, McHugo G, Douglass R, Ohler J, Wasson J, et al. Chief complaint fatigue: a longitudinal study from the patient's perspective. Fam Pract Res f 1987;6:175-87.

12 Wessely S, Powell R. Fatigue syndromes: a comparison of chronic "postviral" fatigue with neuromuscular and affective disorder. 7 Neurol Neurosurg Psychiatry 1989;52:940-8

13 Millon C, Salvato F, Blaney N, Morgan R, Mantero-Atienza E, Klimas N, et al. A psychological assessment of chronic fatigue syndrome/chronic Epstein-Barr virus patients. Psychological Health 1989;3:131-41.

14 Wessely S, David A, Butler S, Chalder T. Management of chronic (post-viral) fatigue syndrome. I $R$ Coll Gen Pract 1989;39:26-9.

15 Butler S, Chalder T, Ron $M$, Wessely S. Cognitive behaviour therapy in chronic fatigue syndrome. $\mathcal{F}$ Neurol Neurosurg Psychiatry 1991;54:153-8.

16 Vincent A, Newsom-Davis J. Acetylcholine receptor antibody as a diagnostic test for myasthenia gravis: results in 153 validated cases and 2967 diagnostic assays. F Neurol Neurosurg Psychiatry 1985;48:1246-52.

17 Nixon DF, Parsons AJ, Eglin RP. Routine full blood counts as indicators of acute viral infections. F Clin Pathol 1987;40:673-5.

18 Yousef GE, Bell EJ, Mann GF, Murugesan V, Smith DG, McCartney RA, et al. Chronic enterovirus infection in patients with postviral fatigue syndrome. Lancet 1988;i:146-50.

19 Zigmond AS, Snaith RP. The hospital anxiety and depression scale. Acta $\overrightarrow{0}$ Psychiatr Scand 1983;67:361-70.

20 Lewis $\mathrm{G}$, Wessely $\mathrm{S}$. Comparison of the general health questionnaire and the $\overrightarrow{\vec{H}}$ hospital anxiety and drepression scale. Br f Psychiatry 1990;157:860-4.

21 McCullough P, Nelder JA. Generalised linear models. 2nd ed. London: Chang and $\mathrm{Hall}, 1989$.

22 Landay A, Jessop C, Lenette E, Levy J. Chronic fatigue syndrome: clinical condition associated with immune activation. Lancet 1991;338:701-12.

23 Wells KB, Stewart A, Hays RD, Burnham A, Rogers W, Daniels M, et al. The of functioning and well being of depressed patients. FAMA 1989;262:914-9. 24 Sharpe M. Psychiatric management of PVFS. Br Med Bull 1991;47:989-1005.

\title{
Association between postpartum thyroid dysfunction and thyroid antibodies and depression
}

\author{
Brian Harris, S Othman, J A Davies, G J Weppner, C J Richards, R G Newcombe, J H Lazarus, \\ A B Parkes, R Hall, D I W Phillips
}

Abstract

Objective-To define the relation between mood and autoimmune thyroid dysfunction during the eight months after delivery.

Design-Double blind comparison of the psychiatric status of women positive and negative for thyroid antibodies. Clinical examination and blood sampling for free triiodothyronine and thyroxine, thyroid stimulating hormone, and thyroid antibody concentrations at four weekly intervals. Psychiatric assessment at six, eight, 12, 20, and 28 weeks post partum.

Setting-Outpatient department of district hospital.

Patients -145 antibody positive women and 229 antibody negative women delivering between August 1987 and December 1989.

Main outcome measures-Thyroid status. Number of cases of mental ill health by the general health questionnaire, research diagnostic criteria, Hamilton 17 item depression scale, hospital anxiety and depression scale, and Edinburgh postnatal depression scale.

Results-Six weeks after delivery the general health questionnaire showed $62(43 \%)$ antibody positive women and $65(28 \%)$ antibody negative women had mental ill health $\left(\chi^{2}=8 \cdot 18, \mathrm{p}<0.005\right)$. Follow up of 110 antibody positive and 132 antibody negative women showed significantly greater depression by research diagnostic criteria in antibody positive women $(47 \%)$ than antibody negative women $(32 \%)$ regardless of thyroid dysfunction. Antibody positive women showed higher mean scores for depression on the Hamilton $(6.01 v 3.89, \mathbf{p}=0.0002)$, Edinburgh $(7.45 v 5.92, \mathrm{p}=0.031)$, and hospital depression scales $(4.95 v 3.79, \mathrm{p}=0.003)$.
Conclusion-Depressive symptoms are asso- $\stackrel{\circ}{\circ}$ ciated with positive thyroid antibody status in the $\overrightarrow{\vec{P}}$ postpartum period.

\section{Introduction}

Transient postpartum thyroid dysfunction asso-s ciated with autoimmune thyroiditis was first reported. in 1976 when Amino et al described six cases in women presenting three to four months after delivery" with signs of mild hypothyroidism. ${ }^{1}$ The symptoms included swelling of the neck, cold extremities, and weight gain. Profiles of serum thyroid hormone concentrations showed the women to have hypo- $N$ thyroidism accompanied by raised titres of thyroid $>$ antibodies. A larger prospective study of over $500 \stackrel{\text {. }}{=}$ women presenting for delivery showed the commonestr clinical conditions to be mild hypothyroidism, hyper-N thyroidism, and occasionally hyperthyroidism fol-o lowed by hypothyroidism. ${ }^{2}$ Other studies have confirmed this, ${ }^{3-6}$ and since thyroid disorders are associated with mood disorders, ${ }^{7-10}$ transient thyroid@ dysfunction could possibly be associated with post 7 natal depression.

Postnatal depression occurs in $10 \%$ to $20 \%$ of women in the postpartum year. ${ }^{11-14}$ Although there is over-疋 whelming evidence that factors such as marital disharmony, lack of a confiding relationship, previous psychiatric illness, housing problems, and other socioeconomic problems are strongly associated,,$^{12}$ as subgroup of women may have a hormonal basis forô their depression. ${ }^{12}$ is Anecdotal support for this has been provided by the finding that the mood of some women with post partum thyroid dysfunction mimics that of "depressive psychosis." Hayslip et al found that women positive for thyroid antibodies 